\title{
Four Score and Seven Years from now: The "Date/Delay Effect" in temporal discounting
}

\author{
Daniel Read \\ Burcu Orsel \\ Department of Operational Research \\ London School of Economics and Political Science \\ Juwaria Rahman \\ Office for National Statistics, UK \\ and \\ Shane Frederick \\ Sloan School of Management \\ Massachusetts Institute of Technology
}

\section{Author notes:}

Address correspondence to either:

Daniel Read, Department of Operational Research, London School of Economics and Political Science, Houghton Street, London, WC2A 2AE . Email: d.read@1se.ac.uk or to Shane Frederick, Sloan School of Management, Massachusetts Institute of Technology, 38 Memorial Drive, Building 56-317, Cambridge, MA 02142. Email: shanefre@mit.edu. 
First published in Great Britain in 2004

by the Department of Operational Research

London School of Economics and Political Science

\section{Copyright $($ ) The London School of Economics and Political Science, 2004}

The contributors have asserted their moral rights.

All rights reserved. No part of this publication may be reproduced, stored in a retrieval system, or transmitted in any form or by any means, without the prior permission in writing of the publisher, nor be circulated in any form of binding or cover other than that in which it is published.

Typeset, printed and bound by:

The London School of Economics and Political Science Houghton Street

London WC2A 2AE 


\begin{abstract}
We describe a new anomaly in intertemporal choice: the "date/delay effect:" Future outcomes are discounted more when time is referred to as a delay (e.g., 'in 6 months') than as a calendar date (e.g. on October $17^{\text {th }}$ ). The effect is demonstrated in four experiments, using both choice and matching response modes. Moreover, hyperbolic discounting is found only when time is referred to as a delay (discount rates are constant when time is referred to in terms of calendar dates). We conclude by suggesting that Rubinstein's (2003) 'similarity' hypothesis as a potential explanation, and then consider some of its practical implications.
\end{abstract}




\section{Four Score and Seven Years from now: The "Date/Delay Effect" in temporal discounting}

Lincoln began his Gettysburg Address with a memorable and powerful phrase: "Four-score and seven years ago." His decision to refer in this way to the time since the founding of a Nation was the product of careful deliberation. He would not have been as happy with "About 90 years ago," or "In 1776."

In a more mundane context, researchers investigating intertemporal choices must also decide how to describe time to their respondents. The y can refer to a temporal interval using units of delay (e.g., days, weeks, months, or years), combinations of these units (e.g., 'one year and six months'), or calendar dates (On July $5^{\text {th }}, 2006$ ). Unlike Lincoln, however, these researchers have not considered how their chosen temporal description will affect the results they obtain. Yet there is abundant evidence, in other domains of judgment and choice, that the way options are described has a profound effect on preferences. For example, identical outcomes lead to risk seeking when they are described as losses relative to an arbitrary reference point, and risk aversion when they are described as gains (Kahneman \& Tversky, 1983); the decision weight put on unitary quantities (such as probability and time) increase when they are decomposed into formally-identical subsidiary components (Read, 2001; Starmer \& Sugden, 1993); and choices between gambles can even be influenced by whether the outcomes are listed in columns or rows (Harless, 1992). The finding of description effects across so many domains, suggests they might occur in intertemporal choice as well.

In this paper, we focus explicitly on the effects of describing time using calendar dates or units of delay. We were prompted by the following passage from 
Robert Strotz's (1955) seminal paper on intertemporal choice (which we put to a use rather different from that intended by Strotz himself):

The relative weight which a person may assign to the satisfaction of a future act of consumption (the manner of discounting) may depend on either or both of two things: (1) the time distance of the future date from the present moment [what we call the delay], or (2) the calendar date of the future act of consumption. The weight I assign to my pleasure in drinking champagne next September 26 may depend either on the fact that that date is a certain length of time away from the present or on the fact that it is my birthday. (p. 167-168)

This passage alerts us to two ways of referring to moment at which outcomes will occur: as delays or calendar dates, each corresponding to different ways of conceptualising that future moment and the interval that precedes it. The concluding sentence in the passage above also suggests that the value we place on future outcomes will depend on which conceptualisation is cued. Strotz goes further by speculating about the direction of this effect:

... To the extent that time-distance is important, I may assign a different (and probably higher) weight to September 26 as it draws nigh; if only the calendar date is important, the weight will not change as that date approaches. (p. 168). In other words, we will discount the future less if we conceptualise time in date terms, than if we conceptualise it in delay terms ${ }^{1}$.

Strotz's explicit purpose when writing the passage above was to summarise a general model of time discounting. Somewhat more formally, the model is as follows:

$$
u\left(x_{i}, t_{i}\right)=\Delta\left(t_{i}\right) u\left(x_{i}, t_{0}\right)
$$


That is, value of an outcome $x_{i}$ that will be received at time $t_{i}$ is the value it would have if received immediately (the undiscounted value, $u\left(x_{i}, t_{0}\right)$ ), weighted by a discount function $\left(0 \leq \Delta\left(t_{i}\right) \leq 1\right)$ that reduces the value of the outcome as a function of the time before it occurs. In the above passage, the present value of Strotz's future champagne consumption is determined by its undiscounted future value which may be affected by particulars of the date (e.g. 'the fact that it is my birthday') and the discount function (i.e., 'the fact that that date is a certain length of time away from the present.') Our interpretation of Strotz's passage suggests that if he had focused his attention entirely on his birthday (the calendar date) then $\Delta\left(t_{i}\right)$ would have been 1 , and there would be no discounting, whereas if he had focused all his attention on the delay, $\Delta\left(t_{i}\right)$ would be less than 1 . The date/delay hypothesis is that when options are described in terms of dates rather than delays, people will put less decision weight on the 'length of time away from the present', with the consequence that people will appear more patient. If people are choosing between options, date descriptions will make them more likely to choose the larger-later over the smaller-sooner one.

In this paper, we describe four experiments testing the date/delay hypothesis. In Experiment 1, we show that people are more likely to choose the larger-later reward when time is referred to as a date than when it is referred to as a delay; In Experiment 2, this is replicated using a matching procedure; and in Experiment 3 we investigate what happens when both dates and delays are simultaneously available. Experiment 4 shows another difference between date and delay references: hyperbolic discounting occurs only when time is referred to as a delay. We postpone our theoretical discussion to the conclusion. 


\section{Experiment 1}

In this experiment, participants chose between smaller-sooner $(S S)$ and largerlater $(L L)$ options. Outcome timing was referred to using either calendar dates or units of delay. There were three temporal-reference conditions, summarised in Table 1. The two delay conditions (Week and Month) covered the same interval as a Date condition. According to the date/delay hypothesis, $L L$ should be chosen more often in the Date condition than in either the Week or Month delay conditions.

\section{TABLE 1 ABOUT HERE}

\section{Method}

Ninety students from the London School of Economics were approached in the library and courtyard, randomly assigned to one of the three conditions described above and asked to check the box of the option they preferred in four questions of the following type:

\begin{tabular}{r|c||c|}
\cline { 2 - 3 } You receive & Option 1 & Option 2 \\
When & Sept 26,2003 & $£ 450$ \\
Your choice: & $\square$ & June 25,2004 \\
& $\square$ \\
\hline
\end{tabular}

Half answered the four questions in the order given in Table 1, and half answered them in the reverse order. 


\section{Analysis}

Consistent with our hypothesis, $L L$ was chosen more often by those in the Date condition than in either the Month or Week conditions (See Table 2). We tested this formally with an ANOVA that included the proportion of choices of $L L$ as the dependent variable, and the three question types (Date, Month, Week) as a betweensubjects factor. The effect of question type was highly significant $(\mathrm{F}[3,111]=8.0$, $\mathrm{p}<.0001$ ), and Tukey post-hoc tests confirmed the story told by the means. In short, there was a clear and very strong date/delay effect.

\section{TABLE 2 ABOUT HERE}

\section{Experiment 2}

In Experiment 1, preferences were elicited using choice. Choice is usually considered the best method for studying preference because it demands the least of the respondent. Another widely used experimental method is matching, where the respondent provides a missing attribute value that will make two options subjectively equivalent, as in the following:

- $\$ 370$ in 17 weeks is equal to $\$ 450$ in weeks (matching on $t_{L L}$ ).

- $\$ 370$ in __weeks is equal to $\$ 450$ in 56 weeks (matching on $t_{S S}$ ).

- $\$ 370$ in 17 weeks is equal to $\$$ in 56 weeks (matching on $x_{L L}$ )

- $\$ \_$in 17 weeks is equal to $\$ 450$ in 56 weeks (matching on $x_{S S}$ ).

Where $t_{L L}$ is the time at which the larger-later outcome $\left(x_{L L}\right)$ will be received, and $t_{S S}$ is the time when the smaller-sooner outcome $\left(x_{S S}\right)$ will be received. Matching tasks 
are theoretically important because they correspond to such real-world activities as pricing, bidding and negotiating.

Research has shown that choice and matching draw on different psychological processes, and consequently that trade-off rates can differ dramatically between them (e.g., Tversky, Sattath \& Slovic, 1988; Frederick \& Shafir, 2004). When matching, respondents may often apply mathematical operations on the numeric attribute values that are sensitive to irrelevant features such as whether the attribute values are exact multiples of one another, and insensitive to relevant features such as whether the numbers refer to hours or minutes of labour (Frederick \& Shafir, 2004). Thus, we could not assume from the choice results in Experiment 1, that the date/delay effect would occur in matching.

\section{Method}

Participants included professionals and students from the London School of Economics and visitors to a local business centre. One hundred sixty completed the questionnaire, with 135 usable responses. ${ }^{2}$ Subjects equated a pair of delayed outcomes where one of the four attribute values $\left(x_{L L}, x_{S S}, t_{L L}\right.$ or $\left.t_{S S}\right)$ was missing. For half of the participants, time was referred to as a calendar date, and for half it was referred to as a delay in months. The instructions were as follows: "Imagine that you will receive some one off payments, which are guaranteed and that you can choose how much you will receive and when" Respondents were then shown an example question like the one below: 


\begin{tabular}{r|c||c|}
\cline { 2 - 3 } You receive: & \multicolumn{1}{|c||}{ Option 1 } & Option 2 \\
When: & August 10,2003 & Nov 24, 2003 \\
\hline
\end{tabular}

They were then told "We want you to fill in the blank to make both options equal to you. In the example above you should state what value for A would make getting A on August 10, 2003 just as good as getting $£ 500$ on Nov 24, 2003.”

Questions were constructed based on a 2 (Temporal reference: Date or Delay) $\times 2$ (Attribute left blank: $x$ or $t) \times 2$ (Timing of attribute left blank: $\cdot S S$ or $\cdot L L)$ design. For each of the two temporal reference conditions, each participant answered four questions, one for every attribute/timing combination. The values used for each question are given in Table 3.

TABLE 3 ABOUT HERE

\section{Analysis}

For each question, a standardized value of the discount function, called a discount factor, was obtained using the following formula:

$$
\delta(.)=\left(\frac{x_{S S}}{x_{L L}}\right)^{1 /\left(t_{L L}-t_{S S}\right)} .
$$

Where time is measured in units of one year. We use $\delta\left(x_{L L}\right)$ to denote values obtained when the larger-later amount was left blank, and so on.

The mean values of $\delta$, collapsed across all questions, are depicted in Figure 1. We analysed the data by means of four $2 \times 2 \times 2$ ANOVAs, one for each question, and the results of these analyses are given in Table 4 . We focus our discussion on the 
major results: The main effect of Temporal reference (date versus delay), the main effect of the Timing of the missing value (whether the subjects were asked to specify an attribute of the more immediate or more delayed reward), and the interaction between Timing and Attribute (whether respondents were matching on time or amount).

\section{FIGURE 1 ABOUT HERE}

TABLE 4 ABOUT HERE

\section{Date/delay effect}

Figure 1 shows a strong date/delay effect. For every matching condition, $\delta$ was higher (that is, there was less discounting) when time was referred to as a calendar date than when it was referred to as a delay. This was confirmed by the ANOVA, which confirmed a strong main effect of temporal reference for every condition.

\section{Additional results}

For all conditions there was a main effect of timing and an interaction between attribute and timing. The main effect, as can be seen in Figure 1, reflects the fact that $\delta$ was lower when matching on time, and the interaction indicates that this effect was entirely due to the very low values of $\delta\left(t_{L L}\right)$. We suggest this pattern reflects an anchoring effect. Tversky, Sattath, \& Slovic (1988) and Delquie (1997) have each suggested that respondents may often generate the requested matching response for the missing attribute by starting with, and then adjusting, the attribute value of the fully specified option (against which the partially specified "matching" option is being 
compared and, ostensibly, equated). In our stimuli, for example, a respondent asked to provide $x_{S S}$ may start with $x_{L L}$, and adjust that downward. To the extent that the final response is "anchored on" or assimilated with the starting value, the adjustment will be "insufficient" in the sense that an attribute will receive more weight when it is the matching dimension than when it is the fully specified dimension (see Delquie, 1997). For our stimuli, this would increase $\delta$ when matching on amount (by decreasing the difference between two amounts) and decrease $\delta$ when matching on time (by decreasing the difference between two times). This can account for the main effect of attribute. It does not, however, explain the the interaction (why the imputed $\delta$ was lower when specifying the time of the later larger reward than when specifying the time of the smaller sooner reward. One explanation, is that when matching on $t_{L L}$ the standard anchoring story applies - people give a time close to $t_{S S}$, thus decreasing $\delta\left(t_{L L}\right)$-- but that when matching on $t_{S S}$ they anchor on the present $t_{0}$ rather than on $t_{L L}$. This will increase the interval between the outcomes, thereby increasing $\delta$ and producing the pattern observed in this study.

\section{Experiment 3}

Experiments 1 and 2 demonstrated the date/delay effect, and showed that whatever distinguishes dates and delays is found in both matching and choice. We now investigate what happens when both the date and delay perspectives are made salient.

\section{Method}

Participants were 90 students from the LSE who were approached in the library and courtyard and asked to complete our questionnaire. 
The method was similar to that of Experiment 1. Participants chose between pairs of outcomes where the times were referred to as either Delays in months, Dates, or as Dates-plus-Delays, as shown below:

\begin{tabular}{|c|c|c|}
\hline & Option 1 & Option 2 \\
\hline You receive: & $£ 900$ & $£ 1200$ \\
\hline \multirow{2}{*}{ When: } & In 4 months & In 20 months \\
\hline & Feb 27, 2004 & June 24,2003 \\
\hline
\end{tabular}

The specific questions used in the experiment are summarised in Table 5.

\section{TABLE 5 ABOUT HERE}

For each participant, we obtained the proportion of times they chose $L L$. As can be seen in Table 6, the pattern was clear. The Date condition yielded many more choices of $L L$ than the Delay condition, and the Date-and-Delay condition was much closer to the Delay condition. An ANOVA on the average proportion choosing LL indicated there were significant differences between the conditions, $F(2,85)=4.29$, $p<.02$, and Tukey post-hoc tests showed that the Date condition differed from the other two conditions, which did not differ from each other.

\section{TABLE 6 ABOUT HERE}

Thus, it appears that when both descriptions are presented concurrently people choose as if they had seen the Delay description only. It leaves open the question of 
how alternate temporal references interact when presented sequentially. If a preference is first formed when a period is described by dates, will it be reversed when a delay description is subsequently presented? If not, how durable is a particular perspective? Presumably, not long, since all those people who showed such large date/delay effects in these experiments would have, both frequently and recently, been exposed to both types of descriptions.

\section{Experiment 4}

Hyperbolic discounting is the hypothesized tendency for the discount factor $\delta$ to increase the farther in the future an outcome is expected to occur (Ainslie, 1975; Strotz, 1955). Hyperbolic discounting predicts that for any pair of rewards separated by a fixed interval (i.e., holding $t_{L L}-t_{S S}$ constant), increasing the onset of that interval $\left(t_{S S}\right)$ will increase the likelihood of choosing $L L$. Most tests of this prediction have referred to time as a delay, and many of these have confirmed the prediction (e.g., Bleichrodt \& Johannesson, 2001; Kirby \& Herrnstein, 1995; Read \& Roelofsma, 2003 Exp 1; Keren \& Roelofsma, 1995 ; Van der Pol \& Cairns, 2002 - though see Ahlbrecht \& Weber, 1997; Baron, 2000; Holcomb \& Nelson, 1992; Read, 2001 Exp 2) ${ }^{3}$. On the other hand, in the few experiments describing time in terms of calendar dates hyperbolic discounting has not been observed (Pender, 1996; Read, 2001; Read \& Roelofsma, 2003 Experiment 2). This pattern of findings suggests there may be a regularity, in which hyperbolic discounting occurs only (or, at least, primarily) when time is referred to using delays. This hypothesis is tested in Experiment 4. 


\section{Method}

In this experiment, discounting was measured using a choice titration method, as described in Read (2001). Participants chose between delayed options and, after each choice, either $x_{L L}$ or $x_{S S}$ was adjusted until an indifference point was reached.

Participants were divided into four groups based on whether time was described as a Date or Delay, and on whether the discounting period was Long or Short. The stimuli are summarised in Table 6 . The periods were divided into 4 intervals that spanned the interval from $t_{i}$ to $t_{i+1}$. For example, in the Short condition the first interval spanned the dates from August 30, 2002 to Nov 29, 2002 (1 month to 4 months), the second interval spanned the dates from Nov 29, 2002 to Feb 28, 2003 (4 months to 7 months), and so on. Hyperbolic discounting predicts that $\delta$ will increase with interval onset.

\section{TABLE 7 ABOUT HERE}

\section{Results}

The mean values of $\delta$ are depicted in Figure 2. As can be seen, $\delta$ was always higher when time is referred to as a date than as a delay. Confirming this, there was a significant main effect of time reference, $F(1,55)=5.6, p<.02$. There was also a main effect of interval, indicating that, consistent with the predictions of hyperbolic discounting, $\delta$ increased for later interval onsets, $F(3,165)=8.1, p<.000$. However, as can be seen in Figure 3, this increase was entirely due to the Delay condition, an observation that is supported by the highly significant Interval by Time reference interaction $F(3,165)=9.4, p<.0001$. 


\section{FIGURE 2 ABOUT HERE}

The last point was investigated more closely by conducting separate ANOVAs for the Date and Delay conditions. As suggested by the discussion above, there was a main effect of interval for the Delay condition, $F(3,87)=13.0, p<.000$, but not for the Date condition, $F(3,78)=2.5, p=.07$. Within-subjects contrasts revealed a strong linear trend for the Delay condition, $F(1,29)=35.1, p<.000$. For the Date condition, on the other hand, there was no significant trend, and in particular no trace of a linear trend, $F(1,26)=0.7$. In short, therefore, the hypothesis that hyperbolic discounting would be observed in the Delay but not the Date condition received very strong support.

\section{Discussion}

In these studies, we showed the 'date/delay' effect: time is treated differently when it is referred to as a specific calendar date than when referred to in terms of delay. Specifically, the date description results in less discounting, and also reveals no evidence of the hyperbolic discounting often found in studies using delay descriptions. We will discuss these results in three parts: First, we discuss a theoretical explanation for these findings, and offer some hypotheses for further research; Next, we consider some practical implications of our results; Finally, we draw some lessons from them concerning how we do research.

\section{Theoretical}

Our studies were primarily designed to test the date/delay hypothesis, not to give a definitive account of why it occurs. However, some guidance can be found in 
recent articles suggesting that observed discounting behaviour is not determined by an underlying discount function, but rather by similarity comparisons between options on the dimensions of time and amount. Specifically, Leland (2002) and Rubinstein (2000, 2003) propose that discounting over an interval is determined by the similarity of the time-points marking its beginning and its end: the more similar, the less discounting. Both authors stress the implications of their hypothesis for hyperbolic discounting. Rubinstein argues that hyperbolic discounting occurs because the similarity between two time-points separated by a common interval increases with the onset of that interval: 12 months is more similar to 11 months than 2 months is to 1 month. The per-unit discount factor $(\delta)$, therefore, increases with interval onset. This account easily fits the findings for the delay conditions of Experiment 4 . If we extend the similarity analysis to non-quantitative comparisons (implied, but not explicitly discussed, by Rubinstein and Leland) it also fits the findings for the date conditions. We suggest the similarity between dates separated by a common interval does not change the later they occur. That is, the similarity of August 13, 2005 to September 22, 2005 is no greater than the similarity of August 13, 2004 to September 22, 2004. Thus, we have hyperbolic discounting for delays, but not for dates.

Can the Rubinstein/Leland hypothesis also enlighten us about the greater patience shown in the date condition? We suggest it can. Take as a single example Question D from Experiment 1 (any question will do equally well): 3 months versus 16 months or August 29, 2003 versus September 24, 2004. If we use a Rubinstein/Leland similarity metric, 3 and 16 months are pretty different, so we should expect lots of discounting. For the date description, however, the story is different. If we used a numerical metric, the dates are quite similar, and certainly more similar than 3 versus 16: 29 is similar to $24 ; 2003$ is similar to 2004 . If we look 
at the non-numerical months they are also similar -- August is adjacent to September in the calendar. Indeed, most pairs of dates will be reasonably similar to one another, and thus lead to relatively little discounting.

This perspective yields new hypotheses. For instance, the discounting associated with dates might be influenced by the way in which they are presented. For example, $8 / 29 / 03$ might be less similar 9/24/04 than $8 / 29 / 2003$ is to $9 / 24 / 2004$ (because the ratio 2004/2003 is much less than 04/03); or August 1, 2003 might be less similar to September 24, 2004 than July 24, 2003 is to September 24, 2004. We leave these speculations, however, for future research, in which judgments of similarity are elicited directly, rather than posited or inferred from responses to intertemporal judgments.

\section{Implications}

The date/delay effect has important practical implications. One lesson is that commercial retailers should refer to temporal outcomes in terms of calendar dates when they want their clients to discount future outcomes very little (e.g. if the buyer must incur unavoidable long shipping delays) and in terms of delays when they want to encourage discounting (e.g. when the seller makes money from express shipping).

These implications may be greatest in the domain of investment and credit offerings. When people think of the future in terms of calendar dates, they will be more likely to invest and less likely to borrow, because there will be less discounting over the interval between the present and the moment when future returns will be received, or future payments must be made. For instance, when offering Bonds, Euro Bills Treasury Bills, and other fixed term securities, it would be better to emphasize the specific listed calendar date on which they mature, as this should reduce 
discounting and increase willingness to invest at a given rate. Conversely, it may be best to offer loans by referring to the delay until the loan comes due as this should make future payments seem more distant, and therefore less onerous. In fact, this is how Bonds and loans are advertised, although we doubt this is a strategic decision ${ }^{4}$. Another implication is that 'buy now, pay later...' schemes should be more attractive when described in delay terms ('pay nothing for 6 months.') than when described using specific dates ('pay nothing until June 2004'). An informal survey of retailers in the UK making such offers found that the vast majority do, in fact, describe their offerings in this way (though again we doubt that this is strategic). ${ }^{5}$

Governments could employ the date/delay effect to convey the attractiveness of savings, and the unattractiveness of debt. It may be more effective to advertise savings by marketing it as "If you put $£ 1000$ in a cash ISA [Individual Savings Account] on the first day of 2004 it will be worth $£ 1500$ by Christmas, 2014," than by marketing it as "If you put $£ 1000$ in a cash ISA today it will be worth $£ 1500$ in less than 11 years." Likewise, to decrease consumer's willingness to incur debt, government regulation could require merchants to specify, in calendar terms, the implications of loans, as in “... on January 28, 2004, February 27, 2004, and the last Friday of every month thereafter until December 29, 2008, you must pay Johnson's Electronics \$100.” Correspondingly, annuity products might seem more attractive when payments are described as being made on a specific date each year.

\section{Conclusion}

Politicians and poets know that the quality and intensity of our responses to acts or events is affected by how they are described. It should not surprise us, therefore, that the way in which we refer to a temporal interval affects time 
preference. Moreover, this finding is unlikely to be limited to the contrast between date and delay descriptions, per se. For instance, dates that are "special" (e.g. may be treated differently than other dates, particularly if the specialness is directly specified (e.g. 'on Christmas 2005,' or 'on your next birthday.') Furthermore, there are still other ways of referring to time, and each may be characterised by its own way of discounting the future. For example, temporal events indexed by a person's future age could be discounted differently than those indexed in other ways: Someone who is 35 , might regard an outcome occurring 15 years away differently than one occurring when they are 50, or one occurring in 2020. The perspective that individuals spontaneously adopt think of the future, when no specific perspective is cued, may even partly explain interindividual differences in discounting.

As a final note, our findings should also serve as a caution to researchers. As discussed earlier, researchers usually choose temporal descriptions for arbitrary or pragmatic reasons. Consequently, we, as researchers, often end up proposing as general truths findings that apply only to the particular descriptions used in their studies, a possibility given weight by the finding, in Experiment 4, that evidence for hyperbolic discounting depends on temporal description. Perhaps we should be more careful to follow the 'operational approach' advocated by Percy Bridgman (1927) almost 80 years ago

If we have more than one set of operations [i.e., way of obtaining a result or measuring a phenomenon], we have more than one concept, and strictly there should be a separate name to correspond to each different set of operations. ( $p$. 10).

When we measure effects in intertemporal choice, or in any other area of judgment and decision making, we should be aware that those effects apply unambiguously only 
to the specific set of operations we have chosen. Date-discounting and delay-

discounting are different concepts ${ }^{6}$, and the implications we draw from one kind of discounting do not necessarily apply to the other. 


\section{References}

Ahlbrecht, M., M.Weber. 1997. An empirical study on intertemporal decision making under risk. Management Science 43(6) 813-826.

Ainslie, G. 1975. Specious reward: A behavioral theory of impulsiveness and impulse control. Psychological Bulletin 82(4) 463-469.

Baron, J. 2000. Can we use human judgments to determine the discount rate? Risk Analysis 20(6) 861-868.

Benzion, U., A. Rapoport, J. Yagil. 1989. Discount rates inferred from decisions - an experimental-study. Management Science 35(3) 270-284.

Bleichrodt, H., \& M. Johannesson. 2001. Time preference for health: A test of stationarity versus decreasing timing aversion. Journal of Mathematical Psychology 45(2) 265-282.

Bridgman, P. W. 1927. The logic of modern physics. New York.

Camerer, C. 1995. Individual decision making. J.H. Kagel, A.E. Roth, eds. The Handbook of Experimental Economics. Princeton University Press, Princeton, New Jersey 587-702.

Frederick, S., G. Loewenstein, T. O'Donoghue. 2002. Time discounting and time preference: A critical review. Journal of Economic Literature 40(2) 351-401.

Frederick, S. \& Shafir, E. 2004. Careless Choice and Mindless Matching: Elusive Attribute Weights in Preference Elicitation” Working paper. Massachusetts Institute of Technology.

Harless, D. W. 1992. Actions versus prospects: The effect of problem representation on regret. American Economic Review 82(3) 634-649.

Holcomb, J. H., \& P. S. Nelson. 1992. Another experimental look at individual time preference. Rationality and Society 4(2) 199-220. 
Kahneman D., \& A. Tversky. 1984. Choices, values and frames. American Psychologist 39(4) 341-350.

Keren, G., \& P.H.M.P. Roelofsma. 1995. Immediacy and certainty in intertemporal choice. Organizational Behavior and Human Decision Processes 63(3) 287297.

Kirby, K. N. 1997. Bidding on the future: Evidence against normative discounting of delayed rewards. Journal of Experimental Psychology - General 126(1) 54-70.

Laibson, D. I. 2002. Intertemporal decision making. URL: http:// post.economics.Harvard.edu/faculty/laibson/papers/ecsmar2.pdf.

Leland, J. W. 2002. Similarity judgments and anomalies in intertemporal choice. Economic Inquiry 40(4) 574-581.

Loewenstein, G. F. 1988. Frames of mind in intertemporal choice. Management Science 34(2) 200-214.

Pender, J. L. 1996. Discount rates and credit markets: Theory and evidence from rural India. Journal of Development Economics 50(2) 257-96.

Read, D. 2001. Is time-discounting hyperbolic or subadditive? Journal of Risk and Uncertainty 23(1) 5-32.

Read, D., \& P.H.M.P. Roelofsma. 2003. Subadditive versus hyperbolic discounting: A comparison of choice and matching. Organizational Behavior and Human Decision Processes 91(2) 140-153.

Read, D. 2004. Intertemporal choice. D. Koehler, N. Harvey, eds. Blackwell Handbook of Judgment and Decision Making Oxford: Blackwell. Rubinstein, A. 2000. Is it Economics and Psychology? The Case of Hyperbolic Discounting. Working paper, University of Tel Aviv/Princeton University. 
Rubinstein, A. 2003. "Economics and Psychology"? The Case of Hyperbolic Discounting. International Economic Review 44(4) 1207-1216.

Starmer, C., R., \& Sugden. 1993. Testing for juxtaposition and event -splitting effects. Journal of Risk and Uncertainty 6(3) 235-254.

Strotz, R.H. 1955. Myopia and inconsistency in dynamic utility maximization. Review of Economic Studies 23(3) 165-180.

Thaler, R. 1981. Some empirical evidence of dynamic inconsistency. Economics Letters 8(3) 201-207.

Tversky, A., S., Sattath, P. Slovic. 1988. Contingent weighting in judgment and choice. Psychological Review 95(3) 371-384.

Van der Pol, M., \& J. Cairns. 2002. A comparison of the discounted utility model and hyperbolic discounting models in the case of social and private intertemporal preferences for health. Journal of Economic Behavior \& Organization 49(1) 79-96. 


\section{Endnotes}

${ }^{1}$ It must be emphasised that Strotz was not explicitly making a claim about temporal description, but only about the two factors that go into time discounting. Inadvertently, he described a significant phenomenon.

${ }^{2}$ Questionnaires were not used if they were incomplete, or if they had at least one response implying a negative discount rate, or an uninterpretable response.

Uninterpretable responses were those in which words were used in place of numbers, times were filled-in when amounts were required, or vice-versa.

${ }^{3}$ Note that this list excludes a large number of studies in which interval length was not held constant.

${ }^{4}$ There are good reasons for the two kinds of presentation that have nothing to do with the date/delay effect. A Euro bill offering is put on the market on one day, and matures on a specific day, and so it is natural - and legally required - to describe the offering in terms of dates. On the other hand, consumer loans are flexible instruments that vary both in the time when they become available, and the repayment term. Again, it is natural to describe the terms in more abstract 'delay' terms.

${ }^{5}$ There was one curious exception. When this passage was first written in December 2003) several retailers were offering 'Buy now, pay nothing until 2005' credit, which is somewhere between date and delay. But 2005 was barely more than 12 months away (and payments are to start in January 2005), and we suspect people will perceive the difference between 2003 and 2005 as greater than 12 months. Within a few weeks, in January 2004, the offer had changed to 'Buy now, pay nothing for 12 months.'

${ }^{6}$ Later, Bridgman asserts about two kinds of measurement: 'The practical justification for retaining the same name is that within our present experimental limits a numerical difference between the results of the two sorts of operations has not been detected. (p. 16)' 
Table 1

Amounts and times used in Experiment 1.

\begin{tabular}{|c|c|c|c|c|c|c|c|c|}
\hline & \multicolumn{8}{|c|}{ Question } \\
\hline & \multicolumn{2}{|c|}{$\mathbf{A}$} & \multicolumn{2}{|c|}{ B } & \multicolumn{2}{|c|}{$\mathrm{C}$} & \multicolumn{2}{|c|}{ D } \\
\hline & $S S$ & $L L$ & $S S$ & $L L$ & $S S$ & $L L$ & $S S$ & $L L$ \\
\hline Amount(£) & 370 & 450 & 520 & 740 & 770 & 1480 & 900 & 1200 \\
\hline Date & $\begin{array}{l}\text { Sept 26, } \\
2003\end{array}$ & $\begin{array}{c}\text { June } 25 \\
2004\end{array}$ & $\begin{array}{c}\text { July } 25, \\
2003\end{array}$ & $\begin{array}{c}\text { Nov 26, } \\
2004\end{array}$ & $\begin{array}{c}\text { Nov 28, } \\
2003\end{array}$ & $\begin{array}{c}\text { May 26, } \\
2006\end{array}$ & $\begin{array}{c}\text { Aug 29, } \\
2003\end{array}$ & $\begin{array}{c}\text { Sept } 24 \\
2004\end{array}$ \\
\hline Months & 4 & 13 & 2 & 18 & 6 & 36 & 3 & 16 \\
\hline Weeks & 17 & 56 & 9 & 78 & 26 & 156 & 13 & 65 \\
\hline
\end{tabular}


Table 2

Percent choosing the later (LL) amount given different descriptions of time period in Experiment 1

\begin{tabular}{cccc}
\hline & \multicolumn{3}{c}{ Description } \\
\cline { 2 - 4 } Question & Date & Month & Week \\
\hline A & 60 & 29 & 14 \\
B & 63 & 18 & 07 \\
C & 60 & 43 & 32 \\
D & 53 & 18 & 21 \\
\hline Mean & $59^{1}$ & $27^{2}$ & $19^{2}$ \\
N & 30 & 28 & 28 \\
\hline
\end{tabular}

Numbers in a row with a common superscript do not differ significantly by Tukey HSD test. 
Table 3

Amounts and times used in Experiment 2.

\begin{tabular}{lccccccccc}
\hline & \multicolumn{1}{c}{ Question } \\
\cline { 2 - 10 } & \multicolumn{2}{c}{ A } & & B & & C & & D \\
\cline { 2 - 10 } & SS & LL & SS & LL & SS & LL & SS & LL \\
\hline Amount in $£$ & 370 & 450 & 520 & 740 & 70 & 1480 & 900 & 1200 \\
Date & Oct 31, & July 7, & Aug 29, & Dec 31, & Dec 26, & June 30, & Sept 26, & Oct 29, \\
Delay & 2003 & 2004 & 2003 & 2004 & 2003 & 2006 & 2003 & 2004 \\
(months) & 4 & 13 & 2 & 18 & 6 & 36 & 3 & 16 \\
\hline
\end{tabular}


Table 4

Analyses of variance for all Questions in Experiment 2. All df $=(1,127)$

\begin{tabular}{|c|c|c|c|c|c|c|c|c|}
\hline & \multicolumn{8}{|c|}{ Question } \\
\hline & \multicolumn{2}{|c|}{$\mathbf{A}$} & \multicolumn{2}{|c|}{$\mathbf{B}$} & \multicolumn{2}{|c|}{ C } & \multicolumn{2}{|c|}{ D } \\
\hline & $\boldsymbol{F}$ & $p$ & $F$ & $p$ & $F$ & $p$ & $F$ & $p$ \\
\hline $\begin{array}{l}\text { Reference: Date versus } \\
\text { delay }\end{array}$ & 18.66 & .00 & 41.65 & .00 & 23.58 & .00 & 29.74 & .00 \\
\hline Timing: $\cdot S S$ or $\cdot L L$ & 6.96 & .01 & 9.67 & .00 & 25.04 & .00 & 3.45 & .07 \\
\hline Att ribute: $x$ or $t$ & 0.27 & .61 & 8.50 & .00 & 20.71 & .00 & 0.00 & .96 \\
\hline $\mathbf{R} \times \mathbf{A}$ & 0.34 & .56 & 0.34 & .56 & 6.95 & .01 & 6.80 & .01 \\
\hline $\mathbf{R} \times \mathbf{T}$ & 0.27 & .60 & 2.31 & .13 & 0.35 & .56 & 0.03 & .86 \\
\hline $\mathbf{T} \times \mathbf{A}$ & 5.72 & .02 & 4.99 & .03 & 11.12 & .00 & 6.19 & .01 \\
\hline $\mathbf{R} \times \mathbf{A} \times \mathbf{T}$ & 0.22 & .64 & 4.89 & .03 & 0.44 & .51 & 1.07 & .30 \\
\hline
\end{tabular}


Table 5

Amounts and times used in Experiment 3.

\begin{tabular}{|c|c|c|c|c|c|c|c|c|}
\hline & \multicolumn{8}{|c|}{ Question } \\
\hline & \multicolumn{2}{|c|}{$\mathbf{A}$} & \multicolumn{2}{|c|}{ B } & \multicolumn{2}{|c|}{$\mathbf{C}$} & \multicolumn{2}{|c|}{ D } \\
\hline & $S S$ & $L L$ & $S S$ & $L L$ & $S S$ & $L L$ & $S S$ & $L L$ \\
\hline Amount (£) & 900 & 1200 & 750 & 2000 & 520 & 780 & 465 & 870 \\
\hline Date & $\begin{array}{c}\text { Feb 27, } \\
2004\end{array}$ & $\begin{array}{c}\text { June 24, } \\
2005\end{array}$ & $\begin{array}{c}\text { April } \\
30,2004\end{array}$ & $\begin{array}{l}\text { Oct } 31 \text {, } \\
2008\end{array}$ & $\begin{array}{c}\text { Dec 26, } \\
2003\end{array}$ & $\begin{array}{l}\text { Oct } 28, \\
2005\end{array}$ & $\begin{array}{c}\text { Mar 26, } \\
2004\end{array}$ & $\begin{array}{c}\text { Feb 23, } \\
2007\end{array}$ \\
\hline Delay (month) & 4 & 20 & 6 & 60 & 2 & 24 & 5 & 40 \\
\hline
\end{tabular}


Table 6

Percent choosing the later (LL) amount given different descriptions of time period in Experiment 3

\begin{tabular}{cccc}
\hline & \multicolumn{3}{c}{ Description } \\
\cline { 2 - 4 } Question & Date & Month & $\begin{array}{c}\text { Date-plus- } \\
\text { month }\end{array}$ \\
\hline A & 47 & 18 & 23 \\
B & 50 & 25 & 33 \\
C & 33 & 21 & 13 \\
D & 30 & 11 & 13 \\
\hline Mean & $40^{1}$ & $19^{2}$ & $21^{2}$ \\
N & 28 & 30 & 30 \\
\hline
\end{tabular}

Numbers with a common superscript do not differ significantly by Tukey HSD test. 
Table 7

Dates, delays and interval lengths in all conditions of Experiment 4

Time points

\begin{tabular}{ccccccc} 
Interval & Reference & $\boldsymbol{t}_{\boldsymbol{1}}$ & $\boldsymbol{t}_{\mathbf{2}}$ & $\boldsymbol{t}_{\mathbf{3}}$ & $\boldsymbol{t}_{\mathbf{4}}$ & $\boldsymbol{t}_{\mathbf{5}}$ \\
\hline \multirow{3}{*}{ Short } & Date & Aug 30, 2002 & Nov 29, 2002 & Feb 28, 2003 & May 30, 2003 & Aug 29, 2003 \\
& Delay & In 1 month & In 4 months & In 7 months & In 10 months & In 13 months \\
\multirow{2}{*}{ Long } & Date & Oct 25, 2002 & Aug 29, 2003 & April 30, 2004 & Jan 28, 2005 & Oct 28, 2005 \\
& Delay & In 3 months & In 12 months & In 21 months & In 30 months & In 39 months \\
\hline
\end{tabular}




\section{Figure 1}

Results of Experiment 2, showing effect of Date and Delay when matching on both amount $\left(x_{S}\right.$ and $\left.x_{L}\right)$ and time $\left(t_{S}\right.$ and $\left.t_{L}\right)$.

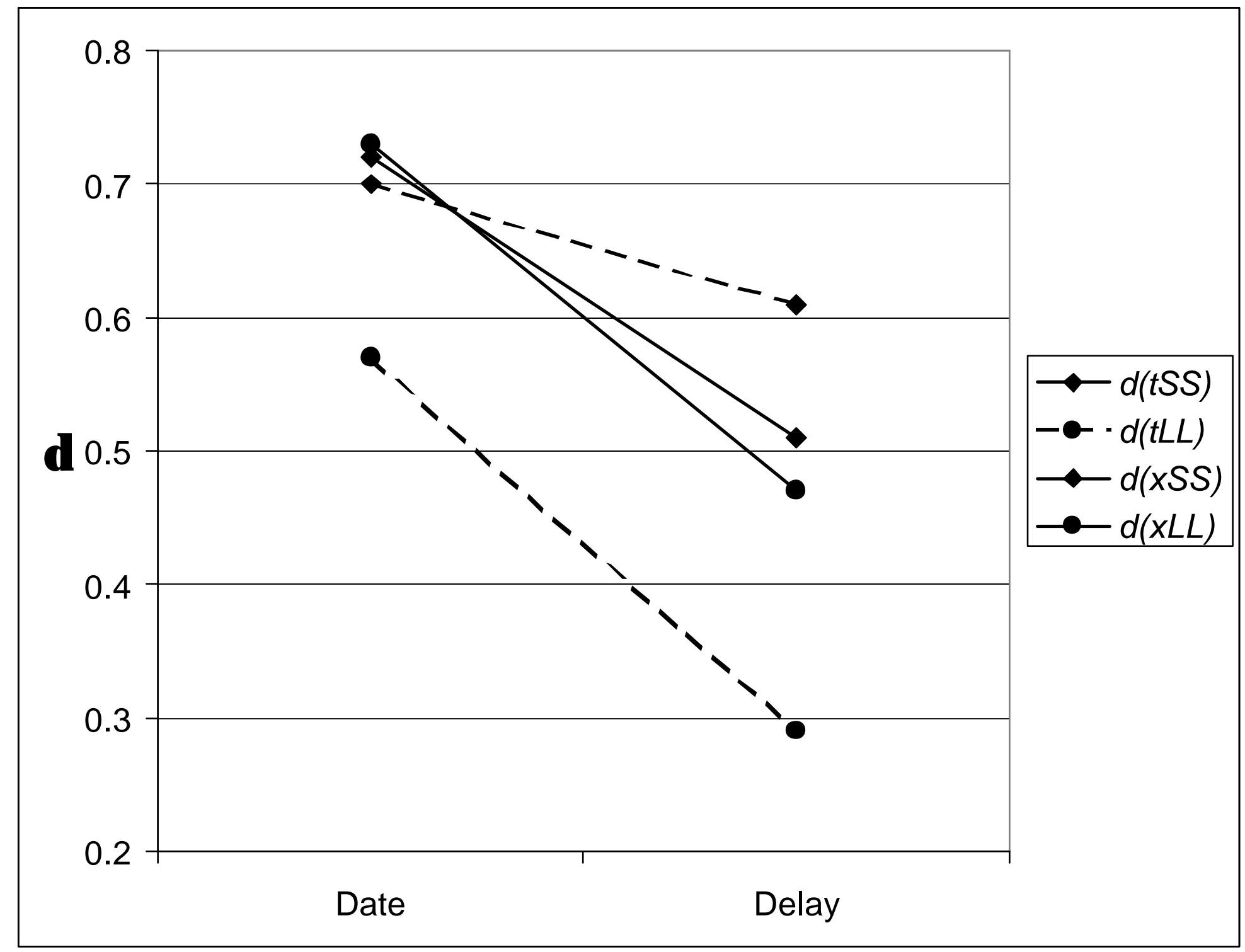




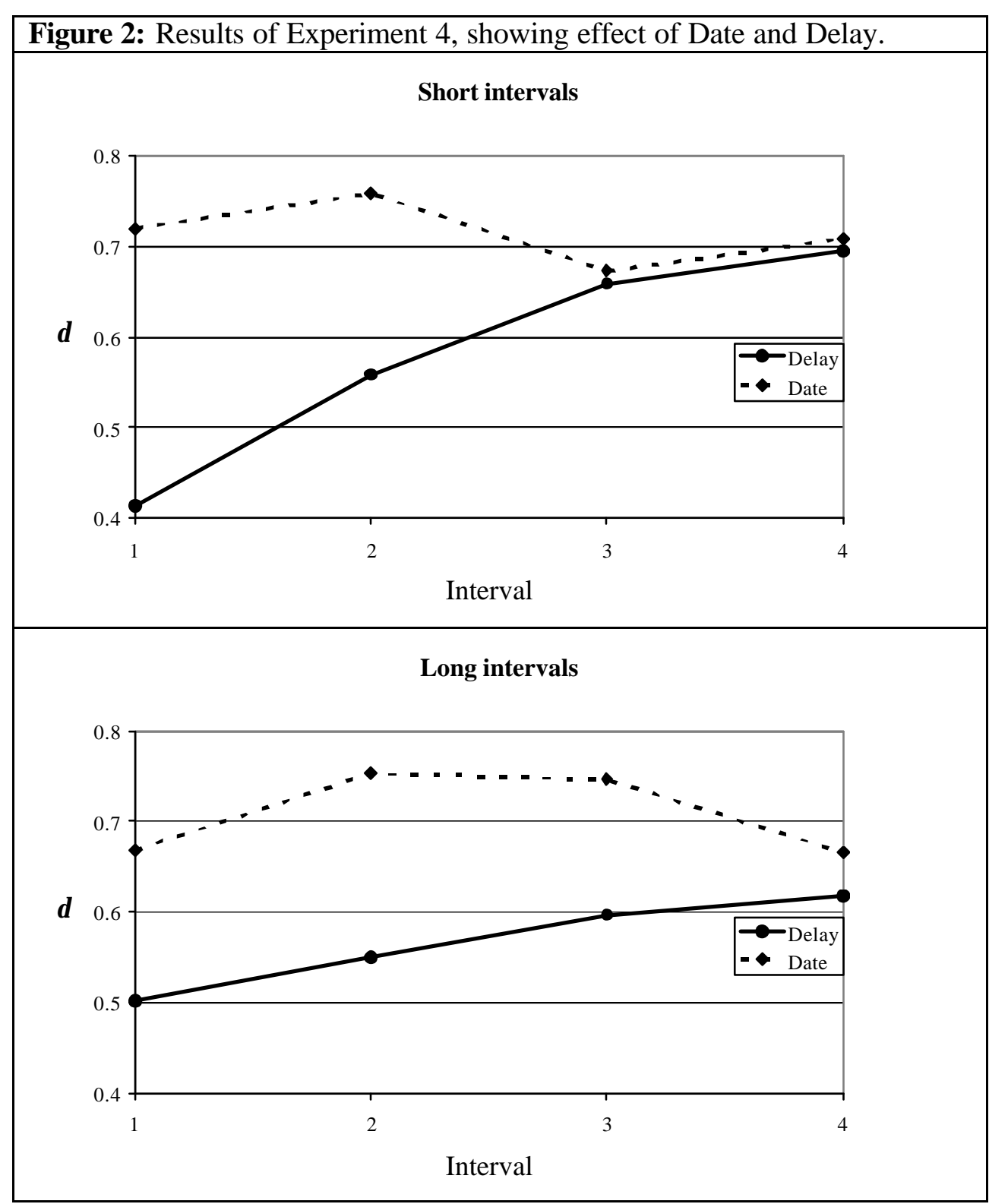



Page 35 